Research Article

\title{
Shaking Table Test on the Seismic Response of Buried Oil and Gas Pipelines under the Bidirectional Nonuniform Seismic Excitation
}

\author{
Jianbo Dai $\mathbb{D}^{1}{ }^{1}$ Chengtao Hu, ${ }^{1}$ Li Wang, ${ }^{2}$ and Guidi Zhang ${ }^{1}$ \\ ${ }^{1}$ School of Mechanical Engineering, Xi'an Shiyou University, Xi'an 710065, China \\ ${ }^{2}$ Shanxi Zhongli Testing and Identification Co., Ltd, Xi'an 710077, China \\ Correspondence should be addressed to Jianbo Dai; 184298843@qq.com
}

Received 8 May 2021; Revised 23 June 2021; Accepted 2 July 2021; Published 9 July 2021

Academic Editor: Daniele Perrone

Copyright (c) 2021 Jianbo Dai et al. This is an open access article distributed under the Creative Commons Attribution License, which permits unrestricted use, distribution, and reproduction in any medium, provided the original work is properly cited.

This paper studies the seismic response of buried oil and gas pipelines under the bidirectional nonuniform excitation. Based on the bidirectional shaking table array test, the loading and testing scheme is designed and developed, analyzing the strain response of the buried oil and gas pipeline under the bidirectional uniform and nonuniform seismic excitation, as well as the acceleration response and displacement response characteristics of the pipeline and the surrounding soil body and their change rule by the test. The test proves to show that the developed bidirectional laminar shear continuum model soil box can meet the requirements of the bidirectional nonuniform seismic excitation and continuous laminar shear deformation of the soil. The peak strains of the pipeline in axial and bending caused by nonuniform excitation are larger than those of the pipeline under uniform excitation, the degree of unevenness in the distribution along the axial direction is greater, and the strain curves are large in the middle and small at both ends along the axial direction of the pipe. The acceleration responses of the pipeline and the soil body under the bidirectional nonuniform excitation are larger than those under the uniform excitation. The acceleration response of both the pipe and the soil under the nonuniform excitation is larger than that under the uniform excitation, and the differences are shown in the transverse and axial directions, the peak acceleration response of the soil body under the nonuniform excitation is about three times that of the transverse direction, and more peak points appear in the axial and transverse acceleration responses of the pipe under the nonuniform excitation as the loading level increases, the peak displacement response of the soil body increases gradually with the height, but the fluctuation range of the peak displacement of the soil body nearby the pipe is larger. The soil displacement curve starts to smooth out when the loading level reaches $1.0 \mathrm{~g}$, and the axial displacement decreases, which indicates that the interaction between the pipe and soil is more intense and the relative motion between the pipe and soil is more obvious under the nonuniform excitation, and the soil is more likely to be damaged and enter the nonlinear stage. Therefore, it is necessary to analyze and design the seismic performance of buried pipes considering the nonuniform seismic excitation.

\section{Introduction}

Buried oil and gas pipelines are called lifeline projects in oil and gas fields. A large number of earthquakes have shown that pipelines not only suffer direct damage during earthquakes but also may produce serious secondary disasters such as fires, explosions, and environmental pollution, so it is important to ensure their safety and reliability under the effects of earthquakes $[1,2]$. Buried oil and gas pipelines are infinitely long structures and the propagation process of seismic waves has a traveling wave effect; i.e., due to factors such as experiencing different medium conditions, the ground vibration propagated to various points in space has a certain time difference, which makes the vibration caused by seismic waves at various points of the structure differ. Therefore, it is necessary to study the seismic safety of buried oil and gas pipelines under nonuniform seismic excitation [3].

Through the use of shaking table tests, understanding and verifying the pipe-soil dynamic model and analyzing the dynamic response characteristics and laws of buried pipelines under earthquake action have become an effective method of studying the seismic performance of buried pipelines $[4,5]$. At present, many scholars have done a lot of research on this 
issue. Zerva et al. [6] analyzed the response of pipelines under random earthquakes, including differential motions between sections connected by joints, displacement and stress of continuous pipelines, and displacement and force variables of the idealized bridge segment, analyzing the incidence angle of seismic waves at different locations in the longitudinal and transverse directions of the pipeline, the arrival time of fluctuations, and the effects of different fluctuation characteristics, and other factors are analyzed. Research results show that the lateral and longitudinal responses of large-diameter pipelines are equivalent. When the span length exceeds the critical at length, the axial and bending stresses of the pipe reach a constant value. Yoshizaki and Sakanoue [7] investigated how EPS (expanded polystyrene) can reduce soil-pipe interactions through experiments. With EPS backfilling, as opposed to ordinary backfilling, the lateral firmness of the pipe can be greatly reduced during earthquakes as the foundation moves, which has a significant effect on improving the seismic performance of buried pipes with elbows under the action of permanent ground deformation (PGD) important influence. Rahimi et al. [8] conducted a series of shaking table tests on elbow buried pipes, and the results showed that under dynamic loads, small diameter buried pipes exhibited more suitable performance than large-diameter buried pipes, and buried pipes with high stiffness and low flexibility were subjected to higher stresses under dynamic loads. Comparing the strains of soil and pipes, two materials with different constitutive behaviors, it can be seen that the axial strain of the soil around the pipes is on average about 10 times greater than the axial strain of the pipe. Jafarzadeh et al. [9] carried out a shaking table test of pipe-soil interaction using a laminar shear box with PVC pipes, using a concrete base mounted at the bottom of the shear box to simulate the nonuniform of real foundations and investigated the effect of dynamic loading on soils and pipes of different materials and compared the axial strain. Larger axial load ratio leads to a larger load-carrying capacity and a weaker deformation capacity. Junyan Han et al. [10] developed a suspended continuum model box suitable for multiple arrays shaking table tests of long linear underground structures, carried out shaking table tests of buried pipelines with multipoint ground vibration inputs under different site conditions, conducted research on the selection of similar relationships in shaking table tests of long transmission buried pipelines and the study of test protocols, and analyzed the seismic response laws of pipelines and sites under consistent and noncoherent seismic effects. It can be seen that although scholars at home and abroad have conducted some researches on the seismic response law of underground pipelines, most of them take consistent seismic input when conducting researches; because oil and gas pipelines are infinite length structures, and there are differences in seismic waves at each place, consistent seismic input will make the research results have large errors. Therefore, considering the spatial and temporal characteristics of the ground-motion traveling wave effect and based on the actual operating environment of buried pipelines, the research on the seismic performance of pipelines still needs to be further developed.

In this paper, we developed a bidirectional laminar shear continuum model soil box that can realize the laminar shear effect of soil and is suitable for noncoherent seismic excitation test, which can simulate the laminar shear performance of soil under real earthquake. Before the test, the pipeline is pressurized to simulate the actual operation of the pipeline, and the shaking table test is conducted under the bidirectional consistent and noncoherent seismic excitation to study the change process of seismic response of buried oil and gas pipeline under bidirectional noncoherent seismic excitation and reveal its seismic response characteristics and laws.

\section{Experimental Overview}

2.1. Test Soil Box and Similar Ratio Design. The test was conducted on the horizontal bidirectional seismic simulation shaking table array system at the Key Laboratory of Structural Wind Resistance and Vibration Control in Hunan Province, which has a table size of $1000 \mathrm{~mm} \times 1000 \mathrm{~mm}$, a maximum load of $50 \mathrm{kN}$ on a single table, and a distance of $2000 \mathrm{~mm}$ between two shaking tables, which can realize bidirectional loading in $X$ and $Y$ directions.

The author developed a bidirectional laminated sheartype continuum model soil box for shaking table testing [11], which includes a laminated frame, a rolling slide device, a limiting device, and an articulated expansion device in conjunction with the test requirements. The Earth box is mainly composed of three parts, of which box No. 1 and box No. 3 are identical, and they are made of 9 layers of $U$-shaped frame stacked together. Each layer of the frame between the shelves has a bull's-eye ball, in order to allow each layer to occur between the layers of misalignment. Each layer of the frame on both sides has bolts, nuts, and a limit plate to form a limit device. The limit plate through the limit of the slide allows each layer of the frame to occur in the slide range. A hinged telescopic device is equipped between each box and each layer of the frame of box No. 2 to make sure that the framework of box No. 2 can achieve the role of telescoping and rotation. Box No. 2 is made of 9 layers of rectangular rods, and there are 12 bull's-eye balls with a diameter of $30.16 \mathrm{~mm}$ at the bottom of the box, which can bear the overall weight of box No. 2 and allow box No. 2 to slide freely when it vibrates without restricting the movement of boxes No. 1 and No. 3. The outer side of the middle section of the box is equipped with a flexible limit to pull rope, which is welded to the outer wall of the rectangular frame after a hole is made in the L-shaped plate and then the layers of the frame are connected together by the limit pull rope.

The overall dimensions of the box are $4000 \mathrm{~mm} \times 840 \mathrm{~mm} \times 944 \mathrm{~mm}$, and a rubber cloth with a thickness of $1 \mathrm{~mm}$ is attached to the inner wall of the box to prevent the soil in the box from seeping out when the shaking table vibrates. The designed and assembled soil box is shown in Figure 1.

The key to the reliability of the test results lies in whether the model test can realize the real seismic response in the room. This test uses the pipe-complete model $S_{E}=S_{l} * S_{\rho}$ and the model soil ignoring the gravity model $S_{g}$

$=1$. Based on the similarity theory, the gauge analysis, and the test environment in the field, the author first 


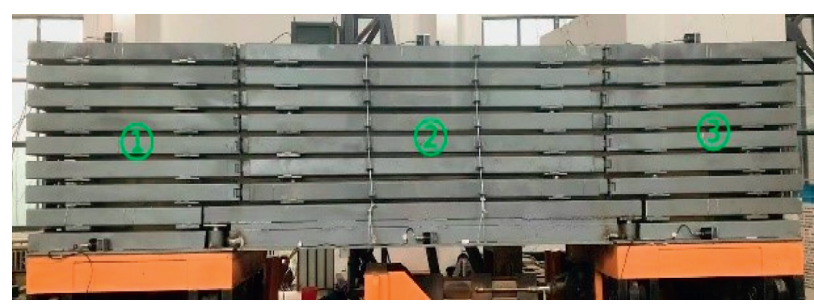

(a)

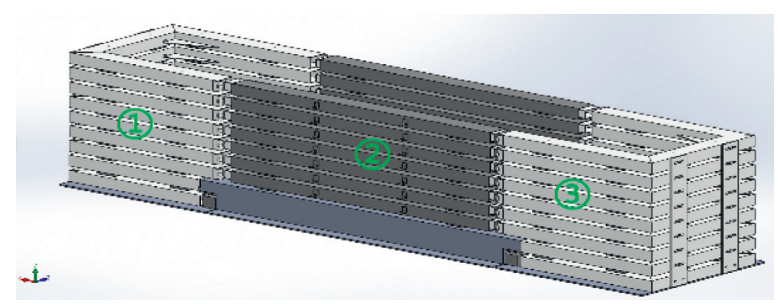

(b)

Figure 1: Bidirectional laminar shear-type continuum model box. (a) Assembled model soil box. (b) Three-dimensional sketch of the model soil box.

determines three constants of the shaking table geometric length, the elastic modulus of the material, and the gravitational acceleration, from which other similarity constants are deduced. The similarity ratio of this model test was determined. Among them, the similarities corresponding to pipe length $l$, modulus of elasticity $E$ of soil, density $\rho$, stress $\sigma$, strain $\varepsilon$, frequency $f$, acceleration $a$, and gravitational acceleration $g$ are shown in Table 1 .

2.2. Test Materials and Equipment. In order to reproduce the real field conditions, the test used an L245 oil and gas steel pipe with a length of $3500 \mathrm{~mm}$ and a cross-sectional size of $140 \times 3 \mathrm{~mm}$. Its material indexes are shown in Table 2. Since the oil and gas transportation pipeline is an infinite length structure, the internal pressure inside the pipeline was pressurized by $8 \mathrm{MPa}$ before the test to simulate the internal pressure on the pipe wall during oil and gas transportation with the two ends of the pipeline being blocked and leaving a pressurized port, as shown in Figure 2. The basic physical parameters of the soil sample were measured, including the density of $1.78 \mathrm{~g} / \mathrm{cm}^{3}$, the water content of $14.1 \%$, compression modulus of 15.09 $\mathrm{MPa}$, the cohesion of $10.6 \mathrm{kPa}$, internal friction angle of 28.5 degrees, and the internal soil size of the box of $3760 \times 600 \times 800 \mathrm{~mm}$.

A total of five data acquisition and analysis systems are used on-site, and the five signal acquisition devices are numbered and distinguished as shown in Figure 3. Among them, device No. 1 (UT) mainly monitors soil pressure, pipe acceleration, and strain at measurement points 20-24; device No. 2 (UT) monitors soil acceleration, displacement, and strain at measurement point 19; device No. 3 (UT) monitors strain at measurement points 9-18; device No. $4(\mathrm{DH})$ monitors part of the soil acceleration; equipment No. 5 (UT) monitors the strain at measurement points $1-8$.

2.3. Sensor Placement. The test mainly measured the strain, acceleration, and displacement seismic response parameters of the pipe-soil body, and the corresponding sensors were resistive strain gauges, capacitive acceleration sensors, and pull-cord displacement sensors. 76 sensors were used in total, including 24 strain gauges, 12 Earth pressure gauges, 18 displacement sensors, and 22 acceleration sensors, and the site layout is shown in Figures 4 and 5.
TABLE 1: Similarity relationship of the test model.

\begin{tabular}{lcccccccc}
\hline Material & $S_{l}$ & $S_{E}$ & $S_{\rho}$ & $S_{\sigma}$ & $S_{\varepsilon}$ & $S_{f}$ & $S_{a}$ & $S_{g}$ \\
\hline Pipeline & $1 / 10$ & $1 / 10$ & 1 & $1 / 10$ & 1 & $3 / 16$ & 1 & 1 \\
Soil & $1 / 10$ & $1 / 4$ & 1 & $1 / 4$ & 1 & 5 & 2.5 & 1 \\
\hline
\end{tabular}

The arrangement of the pipeline strain and acceleration measurement points is shown in Figure 4, along the pipeline, $250 \mathrm{~mm}$ from the left to make a pipeline strain monitoring surface every $600 \mathrm{~mm}$. Totally, there are 6 monitoring surfaces, and each of them is arranged as 4 strain gauges, with a total of 24 strain gauges from S1 to S24. A table acceleration sensor is placed on each of the two shaking tables, making a total of 7 acceleration sensors.

Figure 5 shows the main view and section of the soil acceleration measurement point and displacement measurement point arrangement, three monitoring surfaces are selected along the longitudinal direction of the soil box, $250 \mathrm{~mm}$ from the left to the box boundary, and each monitoring surface is $1130 \mathrm{~mm}$ apart. Each monitoring surface is arranged with 3 acceleration and displacement measurement points from bottom to top, and each measurement point is arranged with axial and transverse sensors, totaling 15 accelerometers and 18 displacement meters, of which M31, M32, and M33 are three-way acceleration sensors, and the remaining M11, M12, and M13 and M21, M22, and M23 are one-way acceleration sensors to monitor the dynamic change performance of each layer of soil and the change of displacement.

\subsection{Shaker Seismic Wave Input and Loading Conditions}

2.4.1. Selection and Input of Seismic Waves. According to the Code for Seismic Design of Buildings, two seismic waves recorded and one artificially synthesized seismic wave were selected for this shaking table test, and the actual recorded seismic waves were the El-Centro seismic wave (E wave) record and the Wenchuan seismic wave (W wave) record. The artificially synthesized seismic wave ( $R$ wave) is based on the response spectrum, and its characteristic period is $0.35 \mathrm{~s}$ according to the Class II site, which is obtained by using MATLAB software to compile the program. The acceleration-time curves of the three different seismic waves are shown in Figure 6. 
TABLE 2: The performance of steel pipe engineering.

\begin{tabular}{lcccc}
\hline Material & Size $(\mathrm{mm})$ & Yield strength $(\mathrm{MPa})$ & Tensile strength $(\mathrm{MPa})$ & Pipeline internal pressure $(\mathrm{MPa})$ \\
\hline 245 steel & $3500 \times 140 \times 3$ & 245 & 415 & 8 \\
\hline
\end{tabular}

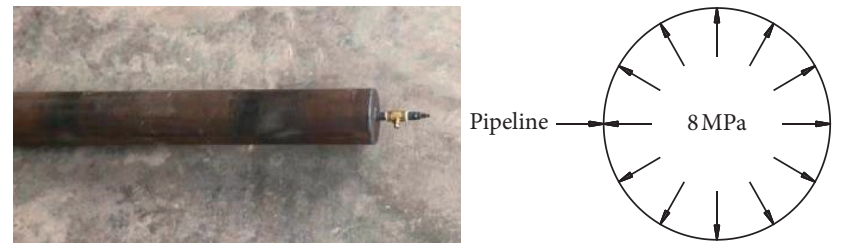

(a)

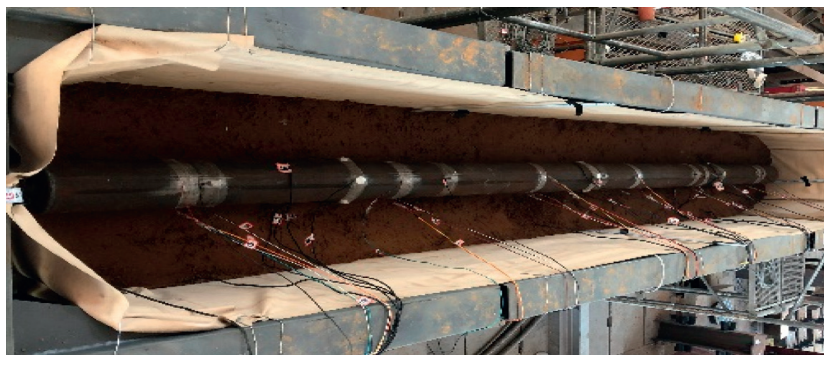

(b)

Figure 2: Shaking table test of the buried pipeline. (a) Schematic diagram of the pressurization port and internal pressure of the pipeline. (b) Pipe embedded in the soil.

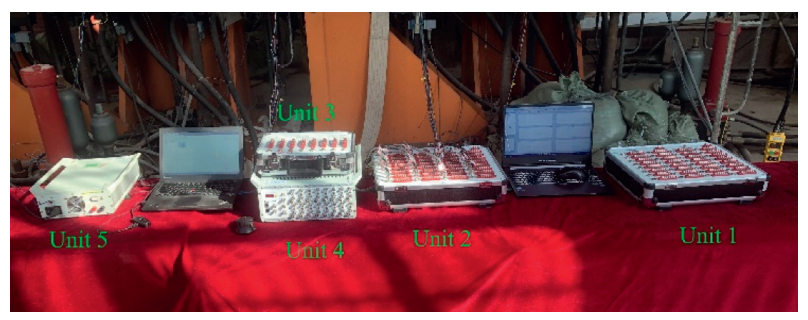

FIgURE 3: The device number map.

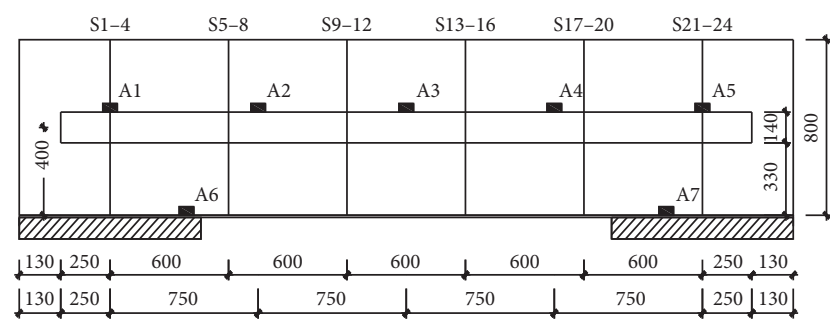

FIgURE 4: Pipeline strain and acceleration sensor layout $(\mathrm{mm})$.

According to the current observations about the response of underground structures during earthquakes and the results of model shaking table tests, it is concluded that the seismic response of underground structures under earthquake action is largely influenced by the surrounding soil, so the ground vibration input is carried out with the similar relationship of soil [12]. In this test, the input acceleration peaks of the original seismic waves were considered according to the acceleration peaks of $0.1 \mathrm{~g}, 0.2 \mathrm{~g}$, $0.4 \mathrm{~g}$, and $0.62 \mathrm{~g}$ corresponding to the seismic intensity of 7 , 8,9 , and 9 degrees of rare encounter of the seismic code in China, and the input acceleration peaks, time intervals, holding times, and frequencies were adjusted according to the similar relationship of the soil in Table 1 . And the actual table input was obtained after the adjustment. The peak acceleration is $0.25 \mathrm{~g}, 0.5 \mathrm{~g}, 1.0 \mathrm{~g}$, and $1.55 \mathrm{~g}$. The input seismic wave durations of El-Centro waves, Wenchuan waves, and artificial waves are $8 \mathrm{~s}, 20 \mathrm{~s}$, and $12 \mathrm{~s}$, respectively, after the conversion of similar relations. To investigate the effects of seismic propagation traveling wave effects, the input seismic waves are kept constant during nonuniform excitation, and the input seismic wave time delay is $1 \mathrm{~s}$ for both shakers.

2.4.2. Shaker Test Loading Scheme. In order to minimize the influence of the accumulated damage of the model caused by multiple vibrations, a step-by-step loading method was used; i.e., El-Centro wave, Wenchuan wave, and artificial wave (E1, W1, R1) were input in each working condition under the same seismic excitation, and the peak acceleration of the table was loaded in steps of $0.25 \mathrm{~g}, 0.5 \mathrm{~g}, 1 \mathrm{~g}$, and $1.55 \mathrm{~g}$. The vibration patterns under consistent seismic excitation and noncoherent seismic excitation were compared, respectively. When the seismic waves were input through the shaking table, the seismic waves were input simultaneously in both transverse and axial directions, and the specific test loading conditions are shown in Table 3.

\section{Experimental Results and Analysis}

3.1. Macroscopic Phenomena of Seismic Response. The observation of macroscopic phenomena of seismic response, such as soil surface damage, is an important tool to assess the seismic-induced site motion, deformation, and the relative motion of the pipe-soil [13]. Under the effect of uniform excitation, the relative motion between the frames of each layer of the box was not obvious, the soil shear deformation was small, and only a small number of cracks appeared when the first-level loading $(0.25 \mathrm{~g})$ and the second-level loading $(0.5 \mathrm{~g})$ were applied. When the third-level loading $(1.0 \mathrm{~g})$ was applied, the magnitude of the box motion increased, the relative shear motion between the frames of each layer was obvious, the soil cracks increased rapidly at the connection between box 1 and box 2 , and the soil at both ends of the box began to damage. At the fourth level of loading $(1.55 \mathrm{~g})$, the 


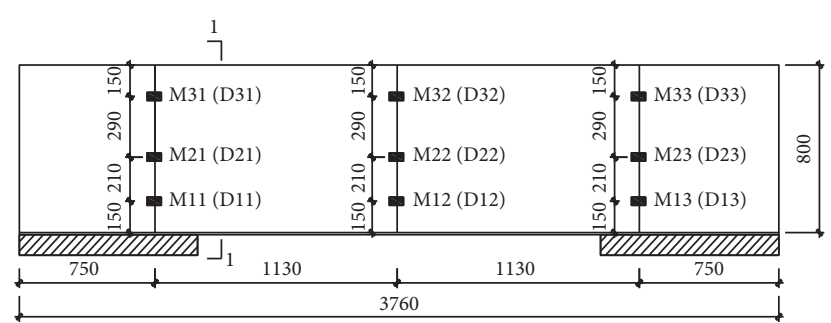

(a)
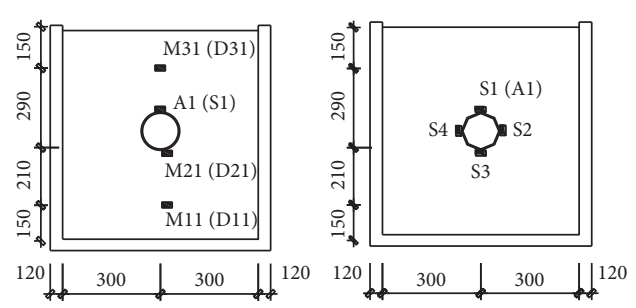

(b)

Figure 5: Soil acceleration and displacement sensor layout. (a) Main view. (b) Profile (mm).
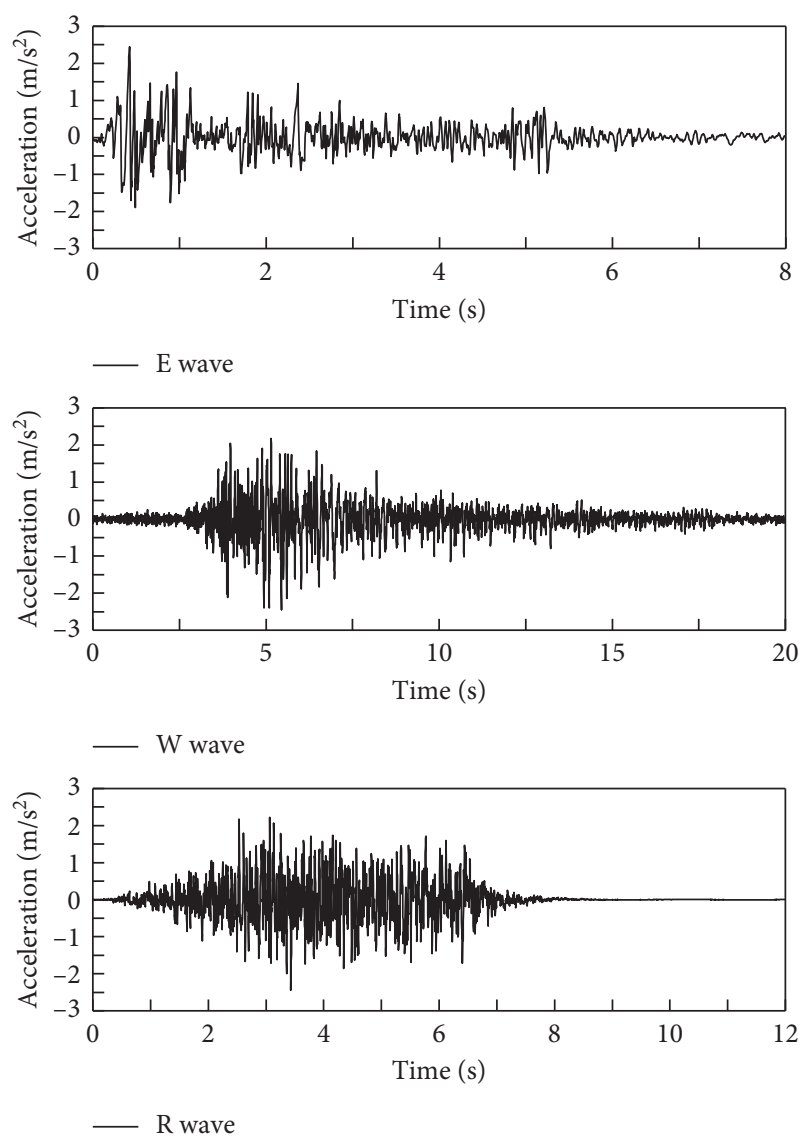

FIGURE 6: Time history diagram of seismic wave acceleration.

box motion intensified, the amplitude of laminar shear deformation increased, the crack width expanded, and the soil structure was seriously damaged.

Compared with the uniform excitation, the box motion was violent at the three-level loading $(1.0 \mathrm{~g})$, the relative displacement between the frames of each layer was obvious, and transverse through cracks appeared at many locations such as the joints between the boxes under the nonuniform excitation; at the four-level loading $(1.55 \mathrm{~g})$, the cracks were continuously extended, the soil damage at both ends of the box was serious, and the collapse phenomenon appeared. At a high loading level, the damage of soil is more serious when there is nonuniform loading. Figure 7 shows the damage of soil surface under uniform and nonuniform bidirectional seismic excitation at the loading level of $1.55 \mathrm{~g}$.
3.2. Pipeline Strain Response Analysis. In the seismic code, the strain can more intuitively reflect the force state and deformation characteristics of the pipeline under seismic excitation [14]. Under bidirectional seismic excitation, the pipe strain response is inconsistent along the pipe axial direction, and the El-Centro wave is used as an example to plot the variation of pipe bending strain and axial strain peak curves along the distance of the measurement point from the left boundary of the pipe under different loading levels, as shown in Figures 8 and 9.

From Figure 8, bidirectional uniform and nonuniform seismic excitations, the peak bending strain curve along the pipeline's axial direction is higher in the center and lower on both ends. When the loading level increases to $1.0 \mathrm{~g}$, the increase in the peak strain of the pipe decreases; the reason is that by the time the loading level reaches $1.0 \mathrm{~g}$, the pipe-soil contact surface is damaged, the slip between the pipe and soil occurs, and the gap increases; then the soil around the pipe enters the nonlinear phase, which leads to the small change in the strain curve at the loading level of $1.0 \mathrm{~g}$ and $1.55 \mathrm{~g}$. The maximum strain peaks of the pipe all appeared at the measurement point $1750 \mathrm{~mm}$ from the left boundary of the pipe, where the peak bending strains under bidirectional consistent and nonconsistent excitation were $39.33 \mu \varepsilon$ and $44.04 \mu \varepsilon$, respectively.

It can be seen from Figure 9 that the peak axial strain curve of the pipeline under bidirectional uniform and nonuniform seismic excitation has the same trend as the peak bending strain curve, but the peak axial strain curve has a greater range of variation. The peak axial strain of the pipeline under bidirectional uniform and nonuniform excitation is $38.81 \mu \varepsilon$ and $46.09 \mu \varepsilon$, respectively, and the peak axial strain of the pipeline under uniform excitation is about $1.3 \%$ lower than the peak bending strain, while the peak axial strain of the pipeline under nonuniform excitation is about $4.4 \%$ higher than the peak bending strain, but the overall difference is not significant.

Overall, the peak strains under nonuniform excitation are larger than those under uniform excitation for both axial and bending strains of the pipe. From the peak strain at the maximum, the seismic excitation has a greater effect on the axial strain of the pipe than the bending strain.

3.3. Pipe-Soil Acceleration Response Analysis. Acceleration response analysis is one of the most important ways to study the site response and the dynamic response of subsurface 
TABLE 3: Loading condition of the shaking table test.

\begin{tabular}{|c|c|c|c|c|}
\hline Test serial number & Incentive mode & Input wave & Loading level (g) & Remarks \\
\hline 1 & Uniform & E1, W1, R1 & 0.25 & 7 degrees \\
\hline 2 & Nonuniform & $\mathrm{E} 2, \mathrm{~W} 2, \mathrm{R} 2$ & 0.25 & 7 degrees \\
\hline 3 & Uniform & E3, W3, R3 & 0.5 & 8 degrees \\
\hline 4 & Nonuniform & $\mathrm{E} 4, \mathrm{~W} 4, \mathrm{R} 4$ & 0.5 & 8 degrees \\
\hline 5 & Uniform & E5, W5, R5 & 1 & 9 degrees \\
\hline 6 & Nonuniform & E6, W6, R6 & 1 & 9 degrees \\
\hline 7 & Uniform & E7, W7, R7 & 1.55 & 9 degrees rare \\
\hline 8 & Nonuniform & $\mathrm{E} 8, \mathrm{~W} 8, \mathrm{R} 8$ & 1.55 & 9 degrees rare \\
\hline
\end{tabular}

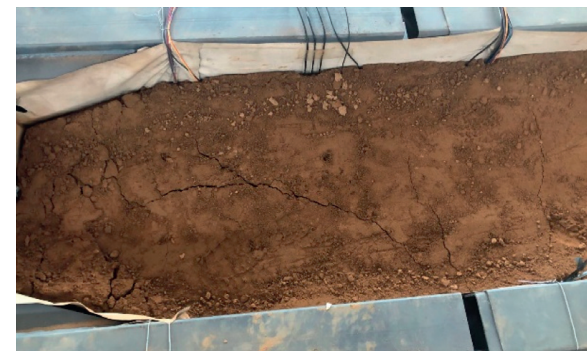

(a)

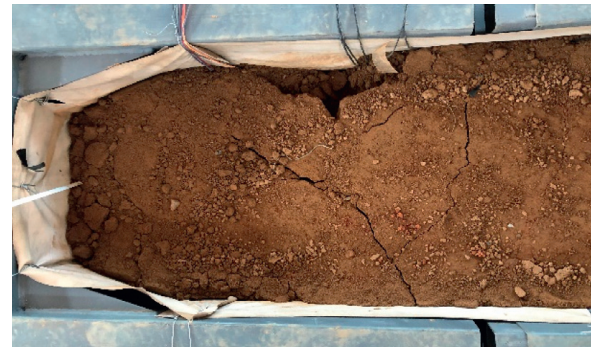

(b)

FIgURE 7: Soil surface damage. (a) Failure of soil under uniform excitation. (b) Failure of soil under nonuniform excitation.

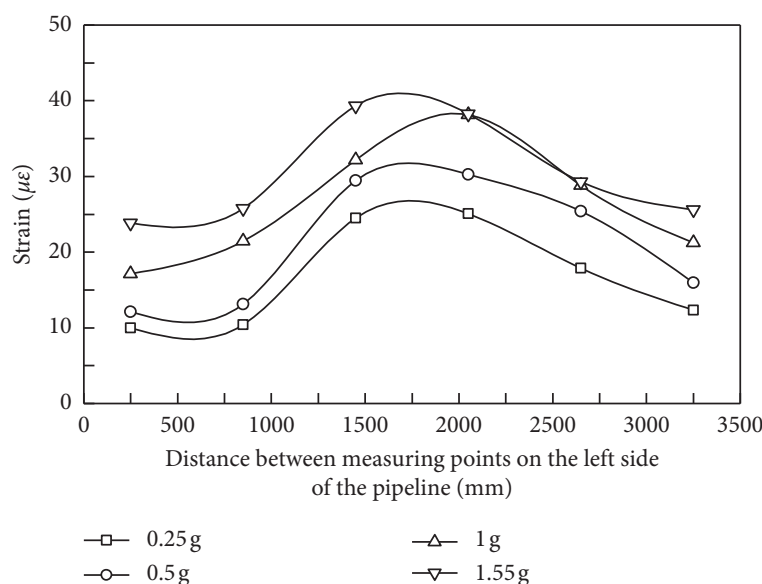

(a)

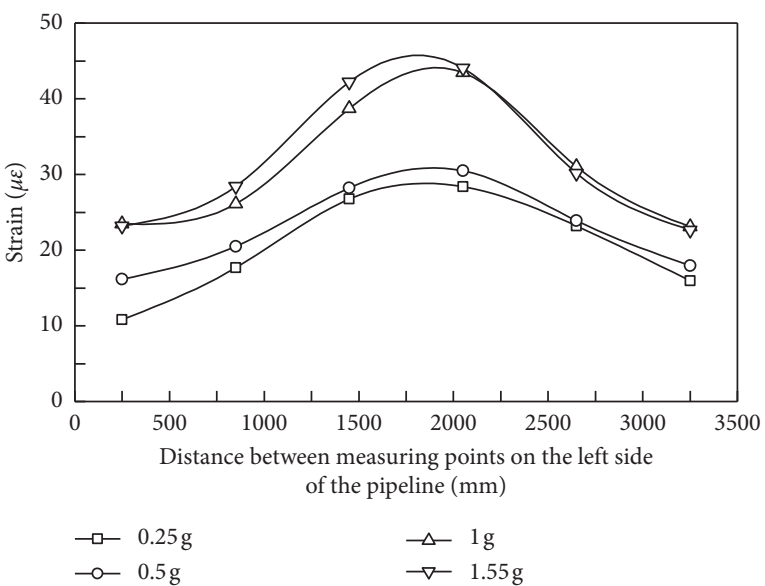

(b)

Figure 8: Peak curve of pipeline bending strain under the bidirectional El-Centro wave. (a) Strain curve of the pipeline under uniform excitation. (b) Strain curve of the pipeline under nonuniform excitation.

structures [15]. To analyze the interconnection of the dynamic properties of the pipe-soil, the pipe-soil measurement points at the same height under El-Centro wave excitation were selected for the analysis, i.e., the measurement points of the middle layer section of the soil (M21, M22, and M23) and the measurement points distributed along the axial direction of the pipeline (A1-A5) for the acceleration response comparison analysis.

3.3.1. Pipeline Acceleration Response Analysis. Figures 10 and 11 show the time course curves of pipeline acceleration response for loading levels of $0.25 \mathrm{~g}$ and $1.0 \mathrm{~g}$, respectively.
The analysis shows that, under the uniform excitation, the waveforms of the measurement points in different directions at $0.25 \mathrm{~g}$ are similar, but the fluctuation range of the axial acceleration response of the pipe is larger compared with the transverse acceleration of the pipe, and the peak value of the axial acceleration of the pipe is about $53 \%$ higher than that of the transverse at the same monitoring point. When the loading level reaches $1.0 \mathrm{~g}$, the peak transverse acceleration response of the pipe is about $19 \%$ higher than the peak axial acceleration response at measurement points $\mathrm{A} 1$ and $\mathrm{A} 2$, while the peak axial acceleration response of the pipe is about $15 \%$ higher than the peak transverse acceleration at other monitoring points. It indicates that the seismic 


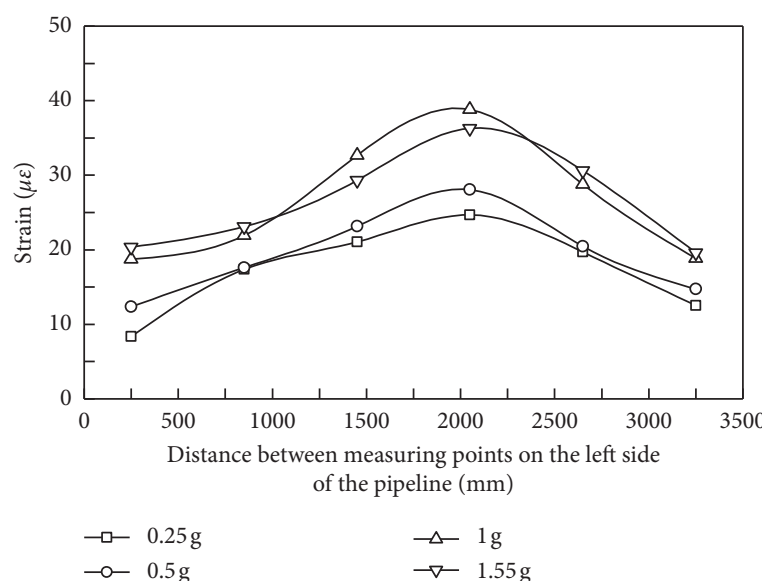

(a)

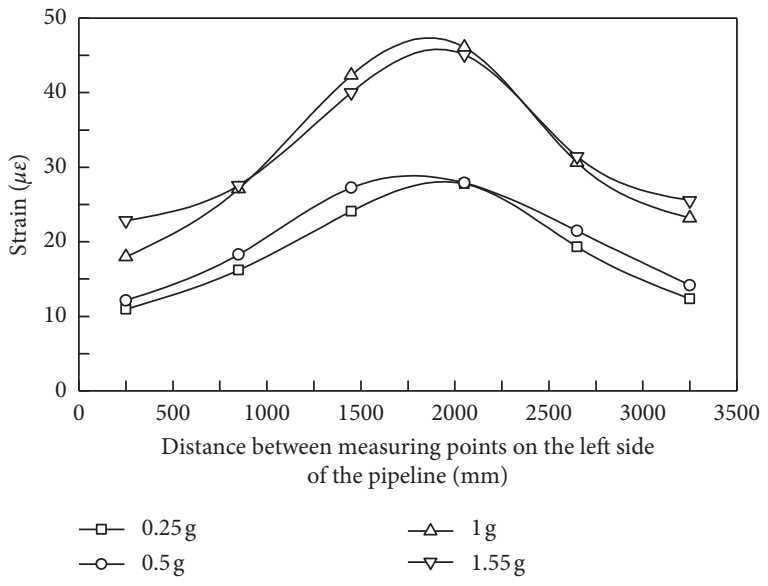

(b)

Figure 9: Peak curve of pipeline axial strain under the bidirectional El-Centro wave. (a) Strain curve of the pipeline under uniform excitation. (b) Strain curve of the pipeline under nonuniform excitation.

excitation has a greater effect on the axial acceleration of the pipe at lower loading levels, while the soil around the pipe enters a nonlinear phase as the loading level increases, resulting in a less significant difference between the peak axial and transverse acceleration responses of the pipe.

Compared with the uniform excitation, the peak transverse and axial acceleration responses of the pipeline under bidirectional nonuniform excitation are larger. When the loading level is $0.25 \mathrm{~g}$, the acceleration response time curve of the pipe under nonuniform excitation is the same as that under uniform excitation, while the peak acceleration of the pipe in the axial direction is about $29 \%$ higher than that in the transverse direction. The similarity of the waveform gets worse when the loading level is increased to $1.0 \mathrm{~g}$. This is because as the loading level increases, the vibration of the pipe under uniform excitation and nonuniform excitation makes a difference, the soil around the pipe is damaged to different degrees, the soil stiffness is weakened, the gap between the pipe and the soil is created, and the vibration becomes more intense, resulting in the similarity of the waveform deteriorating. The peak axial acceleration of the pipe under the axial seismic action is higher than the transverse one only at $\mathrm{Al}$, while the peak transverse acceleration response of the pipe is higher at all other measurement points.

Overall, the peak transverse and axial acceleration responses of the pipe under bidirectional nonuniform excitation are larger than those under uniform excitation, and the effect of seismic excitation on the axial acceleration of the pipe is larger at lower loading levels.

3.3.2. Soil Acceleration Response Analysis. When the loading levels in No. 2 box are $0.25 \mathrm{~g}$ and $1.0 \mathrm{~g}$, the soil acceleration response-time history curves for M21, M22, and M23 measuring points at the same height are shown in Figures 12 and 13.

Under the uniform excitation, comparing the axial and transverse acceleration response peaks of the soil body, it can be found that the acceleration response peaks of the measurement points at M22 are significantly lower than those at M21 and M23 when the loading level is $0.25 \mathrm{~g}$. It may be caused by the motion lag in the middle of the box. At this time, the peak transverse acceleration response of the soil body is higher than that of the axial direction. When the loading level reaches $1.0 \mathrm{~g}$, the peak acceleration response of the soil body increases rapidly, and the peak axial acceleration response exceeds the peak transverse acceleration response because when the loading level is $1.0 \mathrm{~g}$, the soil enters the nonlinear phase and the soil structure is damaged, which is more serious in the axial direction under the bidirectional seismic excitation.

Under nonuniform excitation, the peak transverse and axial acceleration response of soil is not much different from that under uniform excitation at $0.25 \mathrm{~g}$, but it still has a greater effect on the peak transverse acceleration response. When the loading level is $1.0 \mathrm{~g}$, the waveform difference between the acceleration time curves of the soil under nonuniform excitation and under uniform excitation is large. And the reason for this difference is that the interaction between the pipe and the soil under nonuniform excitation is obvious, and violent vibration of the pipe leads to the increase of the gap with the soil, the superposition of the vibration of the soil and the pipe, and the increase of the vibration of the soil, so the soil shows obvious nonlinear characteristics. In particular, the peak axial acceleration response of the soil under nonuniform seismic excitation is about three times higher than that under uniform seismic excitation, and the peak axial acceleration response of the soil is about 1.8 times higher than that in the transverse direction.

By analyzing the acceleration time curves of the soil in different directions under uniform and nonuniform excitation, it can be seen that the peak acceleration response of the soil under nonuniform excitation is higher than that under uniform excitation; especially at higher loading levels, the waveform difference is larger. Regardless of uniform and nonuniform seismic excitation, the seismic excitation has a 


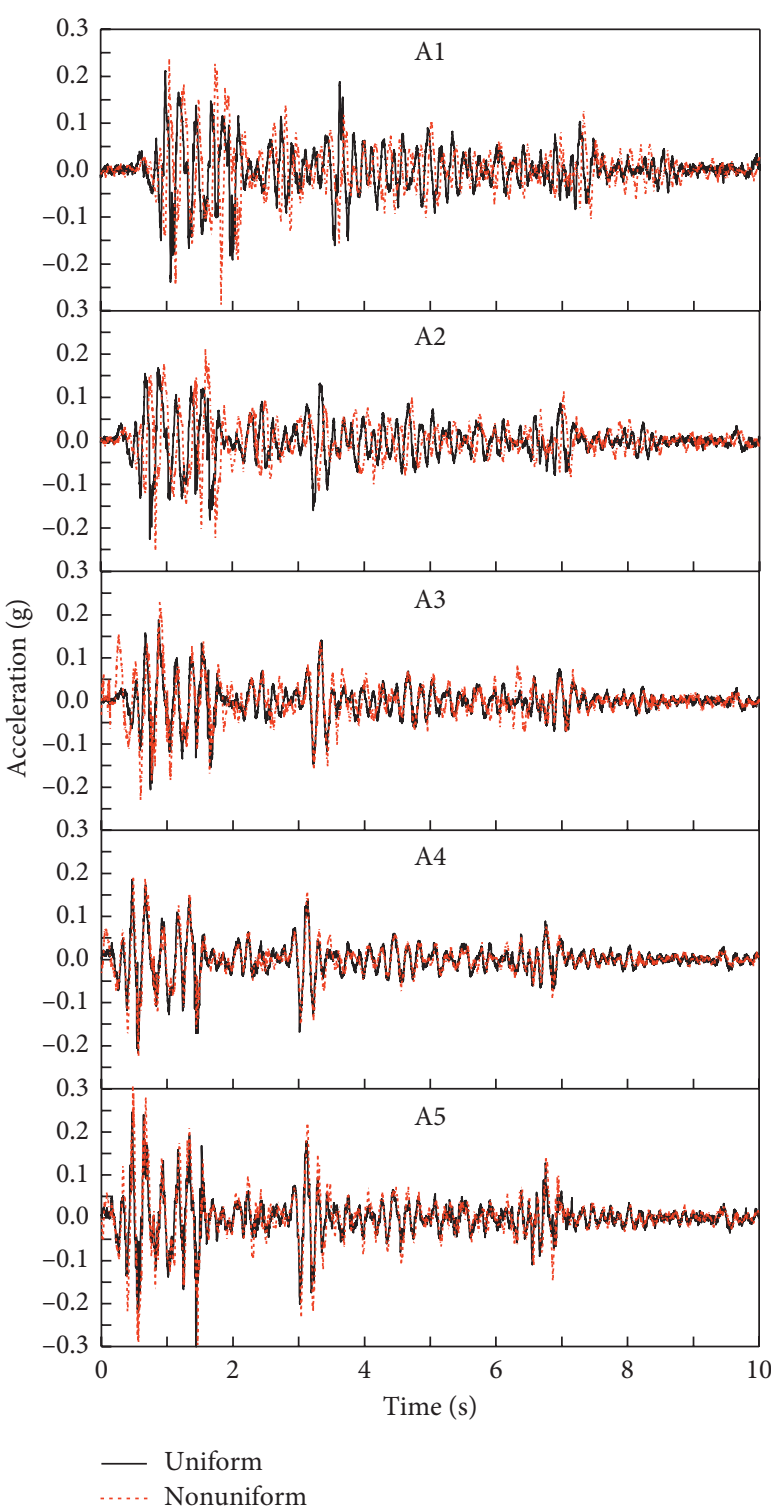

(a)

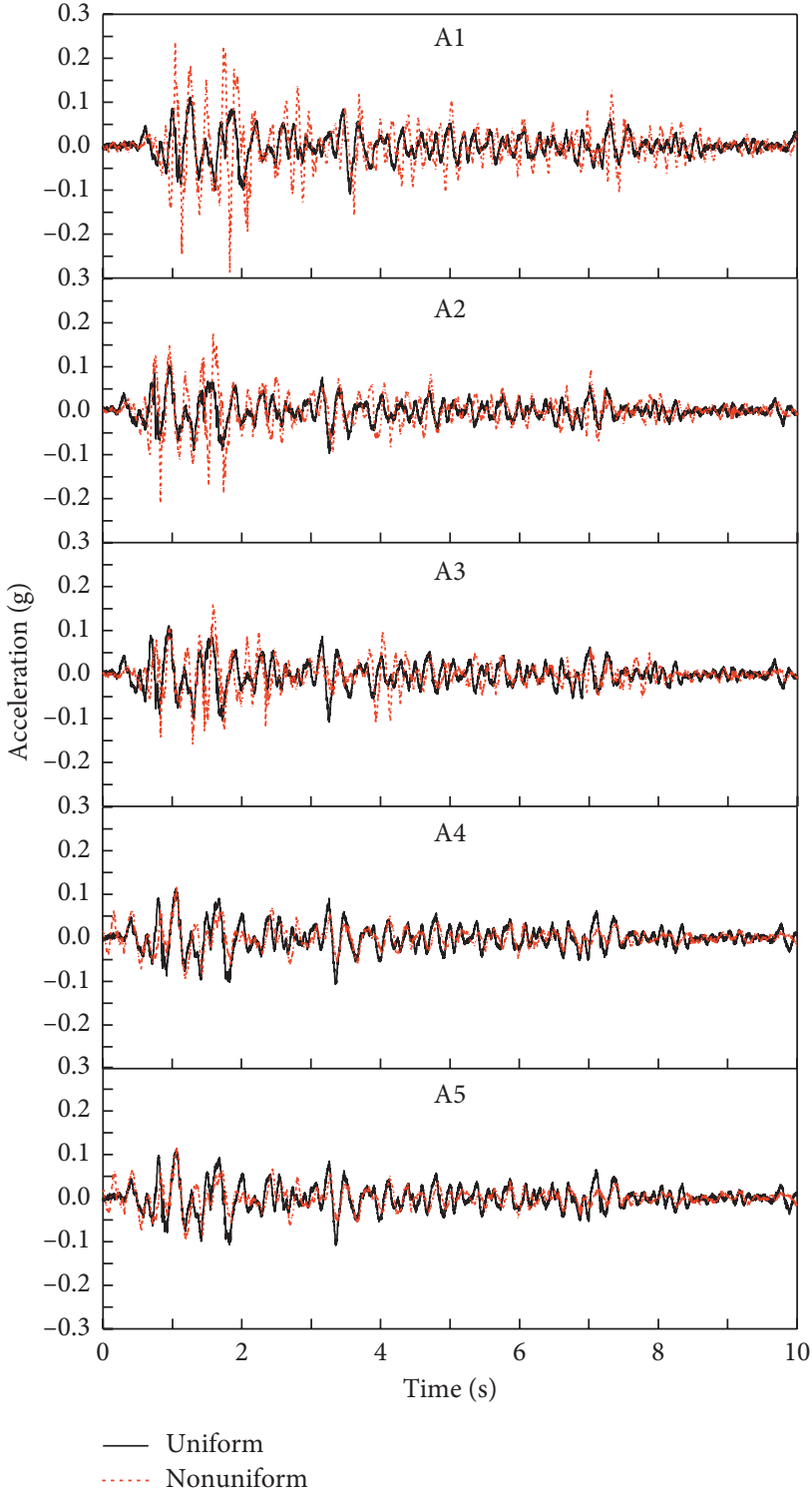

(b)

Figure 10: Acceleration-time history diagram of the bidirectional pipeline under the $0.25 \mathrm{~g}$ El-Centro wave. (a) Time history curve of the axial acceleration response of the pipeline. (b) Time history curve of the transverse acceleration response of the pipeline.

greater effect on the transverse acceleration response at lower loading levels, while the effect of seismic excitation on axial acceleration is larger at higher loading levels.

\subsubsection{Comparative Analysis of Pipe-Soil Acceleration} Response. To reduce the influence of other factors on the acceleration response between the pipe and the soil, the acceleration peak of the pipe acceleration response A3 measurement point in box No. 2 was selected for comparison with the acceleration peak of the soil acceleration response M22 measurement point. As shown in Table 4, when the loading level is $0.25 \mathrm{~g}$, the peak acceleration response of the pipe is larger than the peak acceleration response of the soil in the axial direction and smaller than the peak acceleration response of the soil in the transverse direction, but the overall difference is not large, which means that the pipe is constrained by the surrounding soil at a $0.25 \mathrm{~g}$ loading level, and the pipe follows the common movement of the surrounding soil, due to the large difference between the distance along the transverse direction and the axial direction; thus, the difference between the peak acceleration response of the pipe and the soil appears.

When the loading level is $1.0 \mathrm{~g}$, the peak acceleration response of the pipe is smaller than the peak acceleration response of the soil in the axial direction and larger than the peak acceleration response of the soil in the transverse direction, but the difference between the peak acceleration response of the pipe and the soil is larger at this time, especially under the nonuniform excitation, the peak 


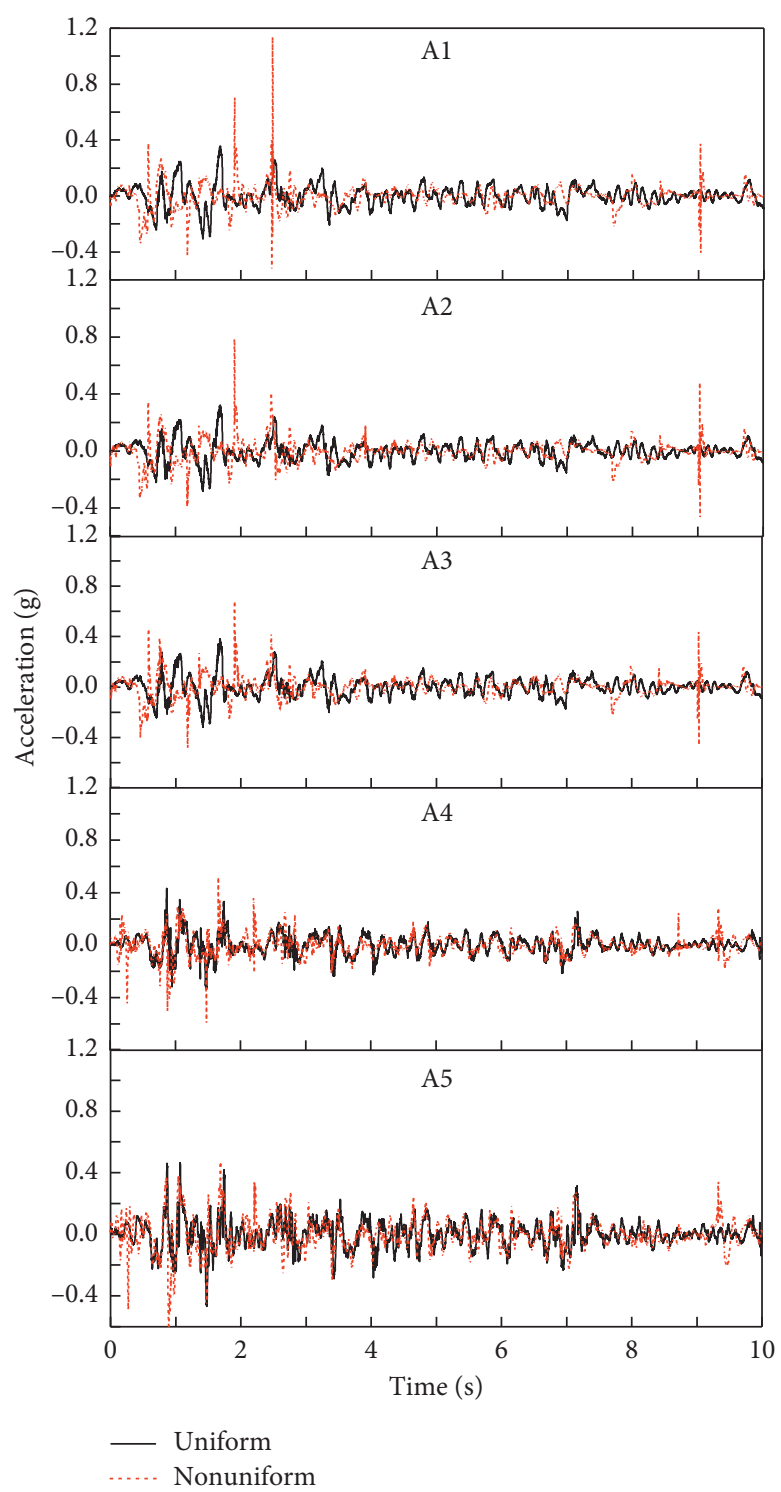

(a)

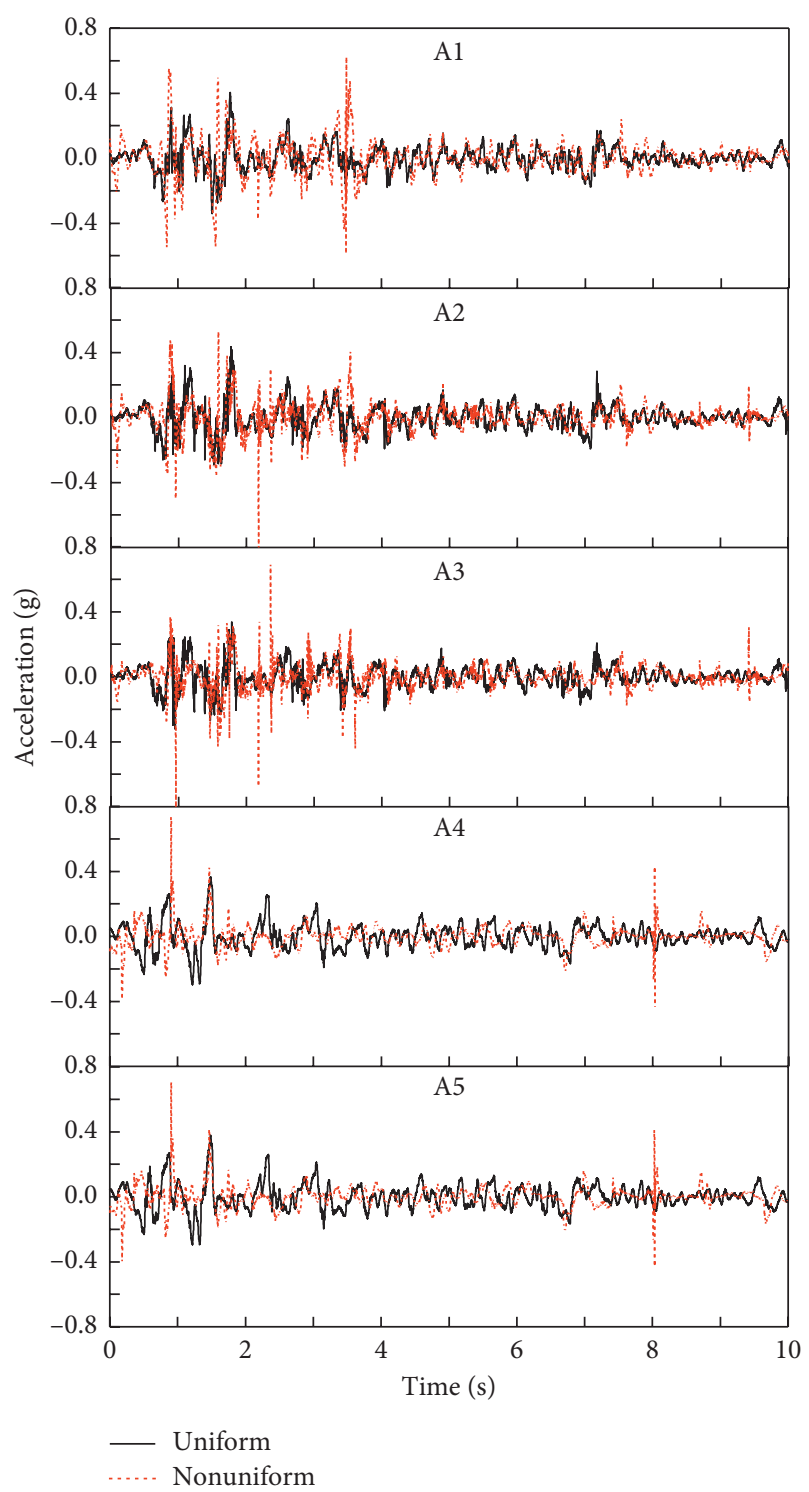

(b)

FIgURE 11: Acceleration-time history diagram of the bidirectional pipeline under the $1.0 \mathrm{~g}$ El-Centro wave. (a) Time history curve of the axial acceleration response of the pipeline. (b) Time history curve of the transverse acceleration response of the pipeline.

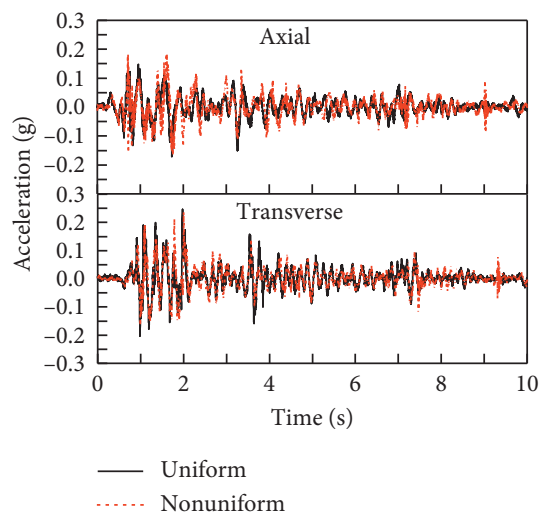

(a)

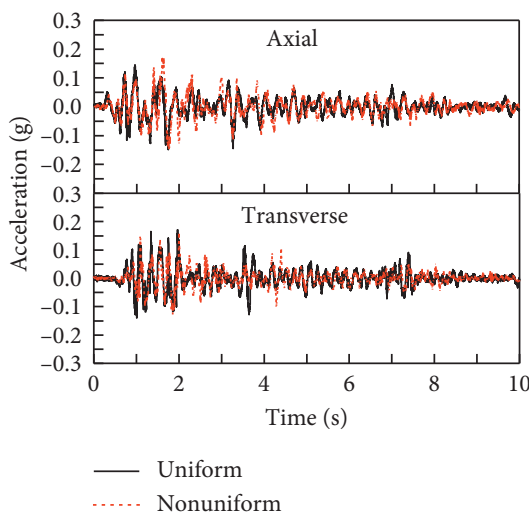

(b)

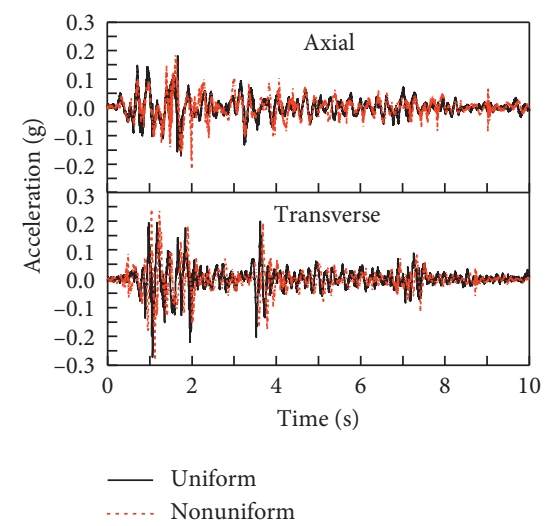

(c)

Figure 12: Acceleration-time history curve of soil under the $0.25 \mathrm{~g}$ El-Centro wave. (a) M21. (b) M22. (c) M23. 


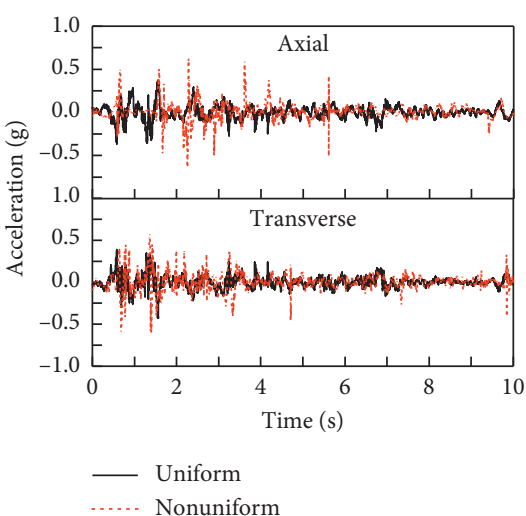

(a)

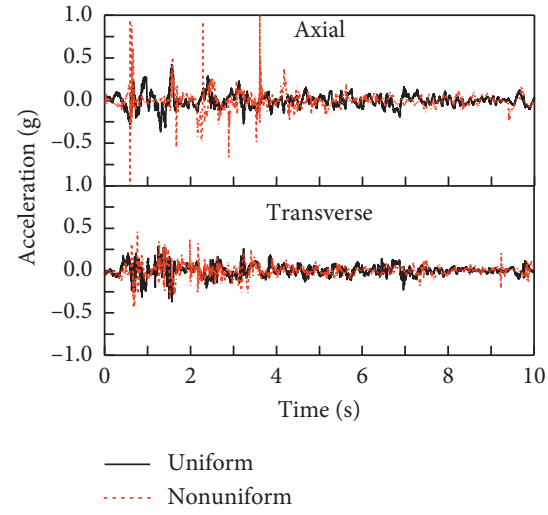

(b)

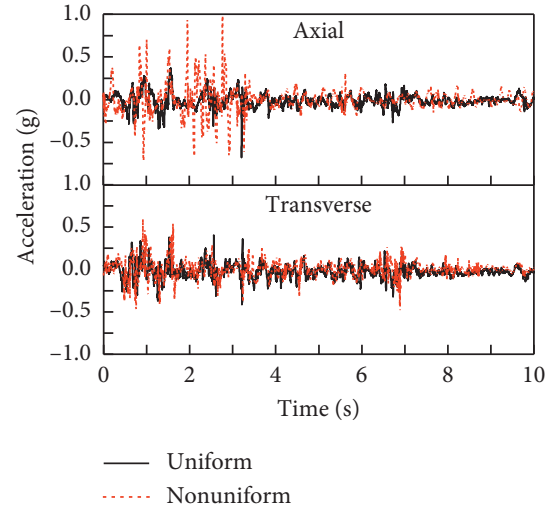

(c)

Figure 13: Acceleration-time history curve of soil under the $1.0 \mathrm{~g}$ El-Centro wave. (a) M21. (b) M22. (c) M23.

TABLE 4: Comparison of peak acceleration of pipes and soils.

\begin{tabular}{lcccccc}
\hline \multicolumn{2}{c}{ Loading level $(\mathrm{g})$} & & $0.25 \mathrm{~g}$ & & \multicolumn{2}{c}{$1.0 \mathrm{~g}$} \\
\multirow{2}{*}{ Axial } & & Uniform & & Nonuniform & Uniform & Nonuniform \\
\hline \multirow{2}{*}{ Transverse } & Pipe & 0.2056 & 0.2306 & 0.3806 & 0.6819 \\
& Soil & 0.1481 & 0.1738 & 0.4220 & 1.1510 \\
& Pipe & 0.1103 & 0.1601 & 0.3354 & 0.2833 \\
\hline
\end{tabular}

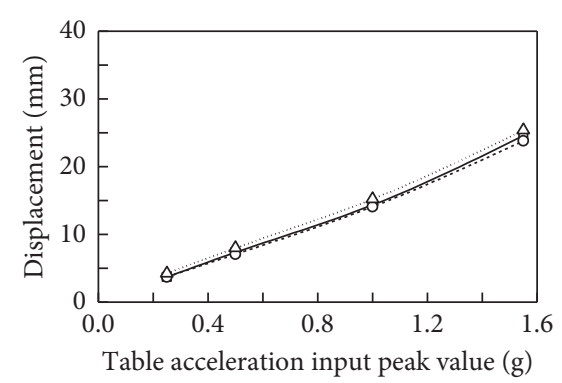

$\rightarrow$ D $12-\mathrm{Y}$

-.o. D D22-Y

$\therefore \Delta \cdot \mathrm{D} 32-\mathrm{Y}$

(a)

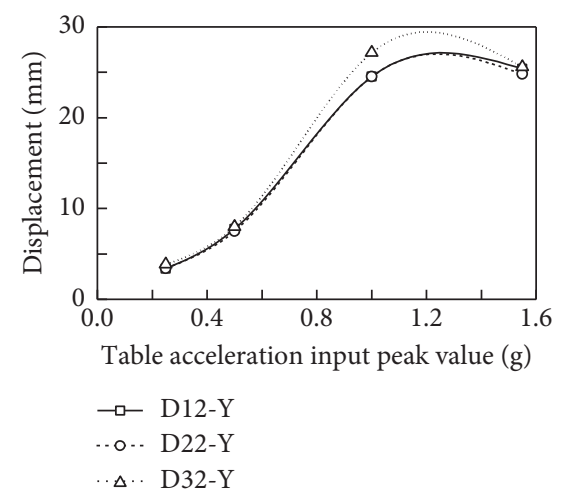

(d)
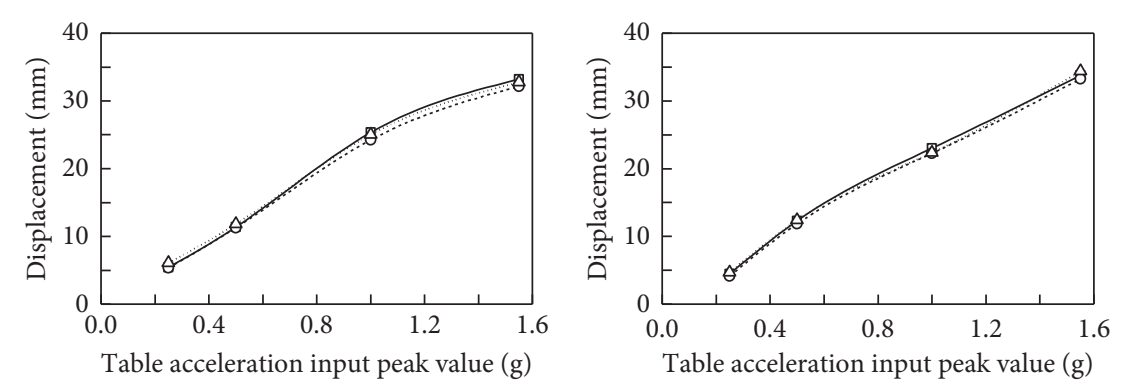

$\rightarrow$ - D12-Y

- o.- D22-Y

A. D32-Y

(b)

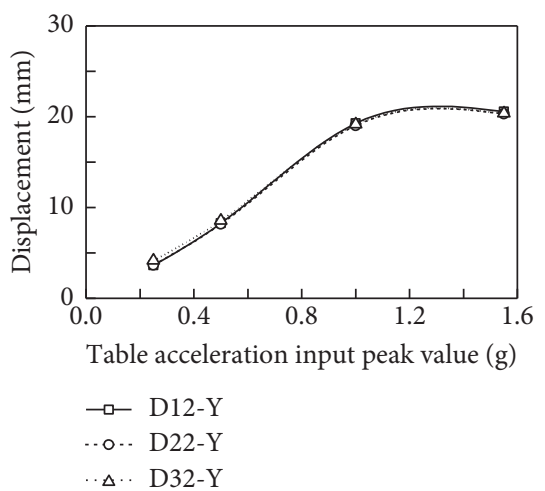

(e) $\rightarrow$ D $12-Y$

.... D $22-\mathrm{Y}$

๑. D32-Y

(c)

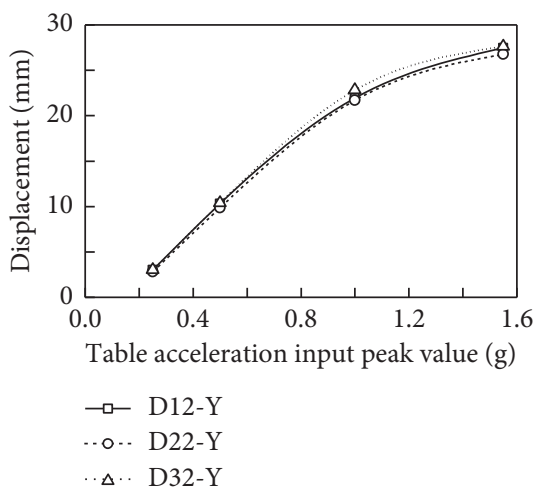

(f)

FIgURE 14: Transverse displacement curves of soils at different heights under uniform/nonuniform excitation. (a) Uniform E wave. (b) Uniform W wave. (c) Uniform R wave. (d) Nonuniform E wave. (e) Nonuniform W wave. (f) Nonuniform R wave. 


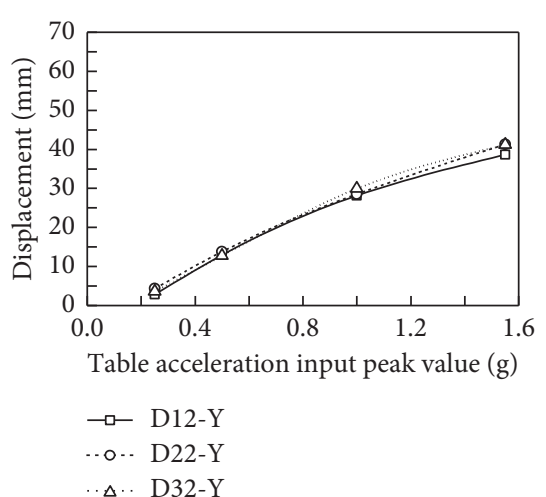

(a)

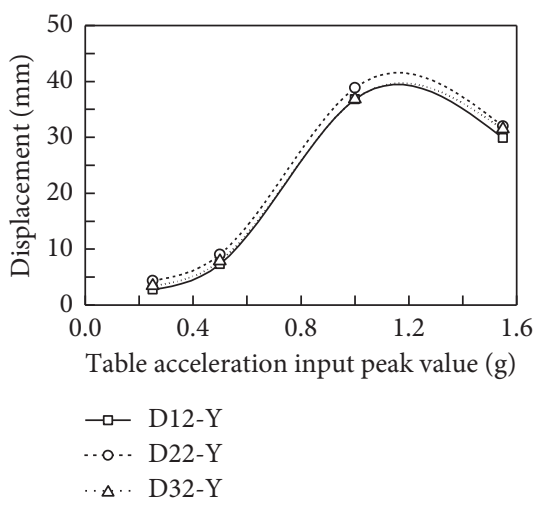

(d)

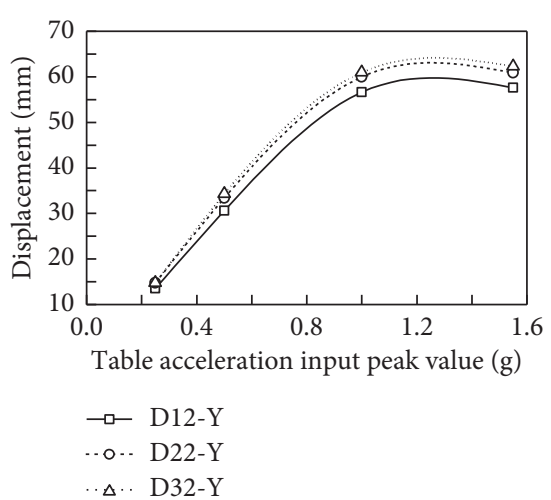

(b)

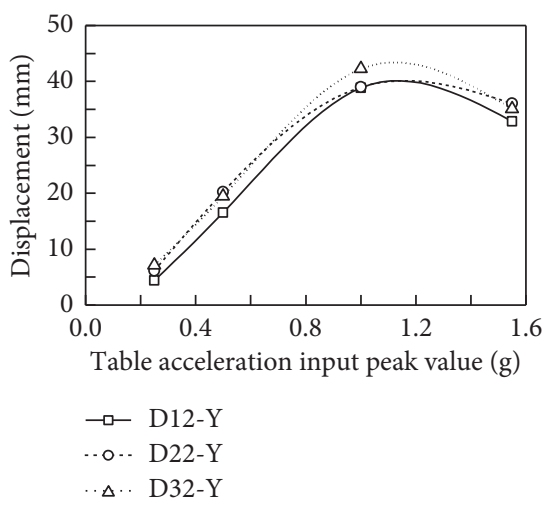

(e)

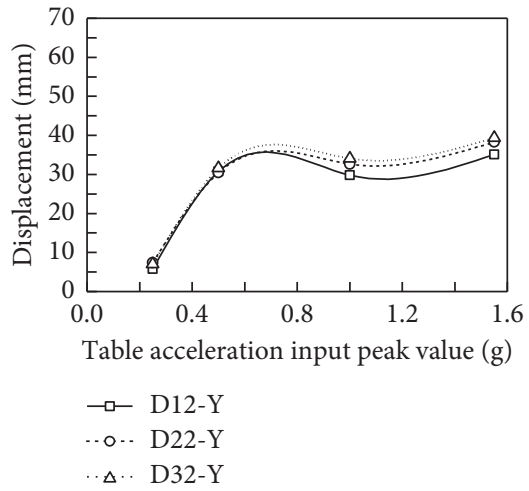

(c)

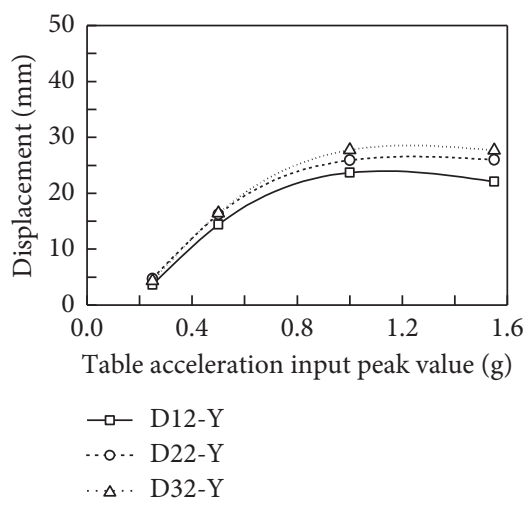

(f)

Figure 15: Axial displacement curves of soil at different heights under uniform/nonuniform excitation. (a) Uniform E wave. (b) Uniform W wave. (c) Uniform R wave. (d) Nonuniform E wave. (e) Nonuniform $W$ wave. (f) Nonuniform $R$ wave.

acceleration response of the soil in the axial direction is about 1.69 times of the peak acceleration response of the pipe, and the peak acceleration response of the pipe in the transverse direction is 2.62 times of the peak acceleration response of the soil, which indicates that the nonuniform excitation has more influence on the lateral pipe-soil interaction and the damage of the soil is more serious. This is consistent with the macroscopic phenomenon observed in Section 3.1, where transverse cracks on the soil surface are more numerous than axial cracks when the table acceleration reaches $1 \mathrm{~g}$, further demonstrating the greater effect of noncoherent seismic excitation on transverse tube-to-soil acceleration.

3.4. Soil Displacement Response Analysis. Soil displacement can reflect the shear deformation of the soil during seismic excitation [16]. The monitoring points (D12, D22, and D32) at different heights within box 2 were selected for monitoring, and Figures 14 and 15 show the curves of soil displacement at different heights with increasing loading levels.

Comparing the transverse displacement curves of the soil at different heights under uniform and nonuniform excitation, it can be found that the curves of soil displacement with loading level are basically the same when different seismic waves are uniformly excited, and the soil displacement increases gradually with the upward movement of height. A pipeline buried nearby the monitoring point D22 affects the displacement response of the soil, the soil displacement here changes abruptly, and its value fluctuates widely. In the nonuniform excitation, the soil displacement curve starts to leveling off when the loading level reaches $1.0 \mathrm{~g}$, which indicates that the soil is more likely to enter the nonlinear phase under the nonuniform excitation.

From the peak soil axial displacement curves under uniform and nonuniform excitation, it is found that the soil shows obvious nonlinear characteristics under uniform excitation of Wenchuan wave and artificial wave, which indicates that the seismic excitation has a greater degree of influence on the axial soil displacement. At the input of nonuniform excitation, the soil displacement decreases at $1.0 \mathrm{~g}$ with the increase of loading level, because of the serious damage of soil structure at this time and the intense strength of interaction between pipe and soil, prompting the obvious relative motion and changing the contact characteristics between pipe and soil, which further indicates the obvious nonlinear characteristics of soil under nonuniform excitation.

\section{Conclusion}

This paper investigates the strain response of buried oil and gas pipelines under bidirectional uniform and nonuniform seismic excitation, the acceleration response and 
displacement response characteristics of the pipeline and surrounding soil, and their change laws based on the shaking table array test of seismic response of buried oil and gas pipelines. The conclusions can be drawn as follows:

(1) Shaking table array tests of buried oil and gas pipelines under bidirectional nonuniform seismic excitation were studied, a bidirectional laminated shear continuum model soil box was developed, and a test scheme was designed. The test results show that the developed model soil box can meet the requirements of bidirectional nonuniform seismic excitation and continuous laminar shear deformation of soil, and the test scheme is reasonable and feasible.

(2) The differences between the axial and bending strains of the pipe caused by bidirectional seismic excitation are small, and they are both large in the middle and small in the ends along the pipe axial direction. The peak axial and bending strains of the pipeline caused by nonuniform excitation are larger than those under uniform excitation, and the peak strains of the pipeline generated by nonuniform seismic excitation are more unevenly distributed along the axial direction, which is the same as the law derived from the shaking table test of multipoint ground vibration input of buried pipeline under different site conditions by Han et al. [10] for the pipeline strains.

(3) When the loading level is low, the axial acceleration response of the pipe and the transverse acceleration response of the soil are larger than those in the other direction, and as the loading level increases, the acceleration response of the pipe in both directions gradually approaches, but the axial acceleration response of the soil is larger than that in the transverse direction; especially under the nonuniform excitation, the peak axial acceleration response of the soil is about three times that of the peak transverse acceleration.

(4) The acceleration response of both the pipe and the soil is greater under the bidirectional nonuniform excitation than that under the uniform excitation, and when the loading level is low, the surrounding soil is stronger in restraining the pipe, and the acceleration response of the pipe and the soil is the same. As the loading level increases, the similarity between the axial and transverse acceleration response of the pipe under uniform and nonuniform excitation becomes worse, more peak points appear in the response curve under nonuniform excitation, the influence on the transverse pipe-soil interaction is greater, and the soil damage is more serious.

(5) Under uniform excitation, the curves of peak soil displacement with loading level are the same for each seismic wave input, the soil displacement increases gradually with the upward movement of height, but the peak soil displacement near the pipe fluctuates more. In the case of nonuniform excitation, the soil displacement curve starts to smooth out when the loading level reaches $1.0 \mathrm{~g}$, and the axial displacement decreases. It indicates that the interaction is more intense, the relative motion is more obvious, and the soil is more likely to be damaged and enter the nonlinear stage between the pipe and soil under the nonuniform excitation.

\section{Data Availability}

The data used to support the findings of this study are available from the corresponding author upon request.

\section{Conflicts of Interest}

The authors declare that they have no conflicts of interest.

\section{Acknowledgments}

This project was funded by the National Natural Science Foundation of China Youth Fund Project (51808446), Key Research and Development Program of Shaanxi (Grant no. 2019SF-266), and Postgraduate Innovation and Practice Training Program Grant of Xi'an University of Petroleum (YCS21113146).

\section{References}

[1] H. Li and J. Wang, "Recent research progress of lifeline seismic engineering," Earthquake Engineering and Engineering Vibration, vol. 37, no. 3, pp. 10-26, 2017.

[2] T. Zirakian, D. M. Boyajian, V. M. Karbhari, and M. G. Melkumyan, "Advances in seismic performance assessment and improvement of structures," Advances in Civil Engineering, vol. 2019, Article ID 9078428, 2 pages, 2019.

[3] J. Dai, G. Lv, and X. Tian, "Dynamic response analysis of long-distance oil and gas pipeline with multi-support seismic excitation," Earthquake resistant engineering and Retrofitting, vol. 39, no. 6, pp. 99-104, 2017.

[4] Y. Shen, B. Wei, and A. Furtado, "Shaking table test study on seismic performance of hollow rectangular piers," Advances in Civil Engineering, vol. 2019, Article ID 7508759, 14 pages, 2019.

[5] S. A. Ali Shah, J. Shah Khan, S. Muhammad Ali, S. Khan, W. Ahmad, and J. Shah, "Shake table response of unreinforced masonry and reinforced concrete elements of special moment resisting frame," Advances in Civil Engineering, vol. 201917 pages, 2019.

[6] A. Zerva, A. H. S. Ang, and Y. K. Wen, "Lifeline response to spatially variable ground motions," Earthquake Engineering \& Structural Dynamics, vol. 16, no. 3, pp. 361-379, 1988.

[7] K. Yoshizaki and T. Sakanoue, "Experimental study on soilpipeline interaction using EPS backfill," in Proceedings of the 2003 ASCE International Conference on Pipeline Engineering and Construction, vol. 2, pp. 1126-1134, Baltimore, MA, USA, July 2003.

[8] S. Rahimi, A. Ghalndarzadeh, K. Bargi et al., "Buried elbow Pipeline/soil interaction under the dynamic loading using $1 \mathrm{~g}$ shaking table test," in Proceedings of the International 
Conference on Civil Engineering and Building Materials, Hong Kong, China, December 2013.

[9] F. Jafarzadeh, H. F. Jahromi, and E. A. Torghabeh, "Investigating dynamic response of a buried pipeline in sandy soil layer by $1 \mathrm{~g}$ shaking table test," International Journal of Civil Engineering, vol. 8, no. 2, pp. 107-124, 2010.

[10] J. Han, B. Hou, Z. Zhong, Mi Zhao, L. Li, and D. Xiu-li, "Study on the test scheme of multiple shaking table array for buried pipelines under multi-point non-uniform excitation," Geotechnics, vol. 40, no. 6, pp. 2127-2139+2153, 2019.

[11] W.-R. Cao, W. Tian, and C. Li, "Development of 2-D laminar shear box and shaking table tests on model soil," Yantu Gongcheng Xuebao/Chinese Journal of Geotechnical Engineering, vol. 39, pp. 249-253, 2017.

[12] X. Du, J. Han, and L. Li, "Selection of similarity relationship in shaking table test design of long-distance buried pipeline," Journal of disaster prevention and mitigation engineering, vol. 33, no. 3, pp. 246-252, 2013.

[13] T. D. O'Rourke, J. K. Jung, and C. Argyrou, "Underground pipeline response to earthquake-induced ground deformation," Soil Dynamics and Earthquake Engineering, vol. 91, pp. 272-283, 2016.

[14] N. Psyrras, A. Sextos, A. Crewe, M. Dietz, and G. Mylonakis, "Physical modeling of the seismic response of gas pipelines in transversely inhomogeneous soil," Journal of Geotechnical and Geoenvironmental Engineering, vol. 146, no. 5, 2020.

[15] X. Zhang and Z. Wang, "Analysis of dynamic seismic behavior and stability of intersection parts of shallow-covered exit/ entrance tunnels of metro works," Tunnel Construction, vol. 30, no. 5, pp. 498-502, 2010.

[16] Z. Zhang, M. Huang, M. Zhang, and W. Wang, "Deformation prediction of the adjacent pipeline due to non-uniform convergence of shield tunneling in layered soils," Yanshilixue $Y u$ Gongcheng Xuebao/Chinese Journal of Rock Mechanics and Engineering, vol. 29, pp. 1867-1876, 2010. 